\title{
Preference and intake of feedstuff by crested porcupines (Hystrix brachyura) in captivity
}

\author{
I Dahlan, AA Salam, BS Amin, A Osman \\ Department of Animal Science, Faculty of Veterinary Medicine and Animal Science, \\ Universiti Pertania Malaysia, 43400 UPM, Serdang, Selangor, Malaysia
}

Porcupines belong to the Rodentia order (which represents the largest order of mammals) and to the suborder Hystricomorpha ("porcupinelike") together with cavies, capybaras, chinchillas and agoutis. Porcupines have been regarded as herbivores or vegetarians, they live chiefly on fruits, supplemented by tubers and leaves. They do not seem to eat grass. Porcupines' feeding behaviour and nutrition including gnawing and other characteristics, have interested biologists. The study of food preferences and feeding habits in captivity will provide information on nutrient requirements of this species. Little about these animals is recorded.

Ten crested porcupines or "Landak raya" (Hystrix brachyura) were captured from the wild. This study involved 5 adult males, 3 adult females and a pair of young animals. These animals were kept in three types of pen, one pair in a big (size $7.3 \times 4.9 \times 4 \mathrm{~m}$ ) pen aviarylike, three pairs were kept in standard pens (size $2 \times 3 \times 2 \mathrm{~m}$ ), and two young ones were kept in individual wire cages (size $1.5 \times 0.6 \times$ $0.56 \mathrm{~m}$ ). They were fed daily with kangkong leaves and stems (Ipomoea reptans) ad libitum, sweet potato tubers (Ipomoea batatas) $300 \mathrm{~g} / \mathrm{d}$, fresh oil palm fruits (Elaeis guineensis) $400 \mathrm{~g} / \mathrm{d}$ and commercial rabbit pellets ad libitum. Feed intake and food selection studies were carried out for a duration of eight months.
No sign of abnormal behaviour and no incidence of nutritional problems was observed during the study period. One birth was recorded after 8 months in captivity with a birth weight of $367 \mathrm{~g}$. The average growth rate of young animals in captivity was $75 \mathrm{~g} / \mathrm{d}$, initial liveweight was $5.0 \mathrm{~kg}$ and final liveweight was $7.1 \mathrm{~kg}$. The average adult weight of male porcupines was $10.35 \pm 0.93 \mathrm{~kg}$ and the average adult weight of female porcupines was $11.47 \pm 0.65$. The preferences for food were as follows; sweet potato > oil palm fruits > kangkong $>$ pellet. Results showed that porcupines in captivity preferred tubers (high NFE $84.5 \%$, DM $26 \%$, CP $6.5 \%$, CF $3.0 \%$ and EE $1.0 \%$ ) and oil palm fruits (high EE $18.0 \%$, DM $42 \%$, CP $7.4 \%$, CF $19.1 \%$ and NFE $53.5 \%$ ) than leafy kangkong (DM $9 \%$, CP $28 \%$, CF $12 \%$, EE $2.7 \%$ and NFE $38.6 \%$ ) and pellet (DM $92 \%$, CP $14.6 \%$, CF $16.5 \%$ and EE $4.6 \%$ ). Results also showed that young growing animal consumed more feed than adult $(P<0.05)$. Restricted feeding of sweet potato and oil paim fruits encouraged the animals to consume commercial pellets and leafy feedstuffs and allowed to maintain the animal performance in captivity. Proper feeding management of the porcupines in captivity is the key of successful breeding colony development. Table below shows feed intake and composition of ration eaten by the porcupines in captivity.

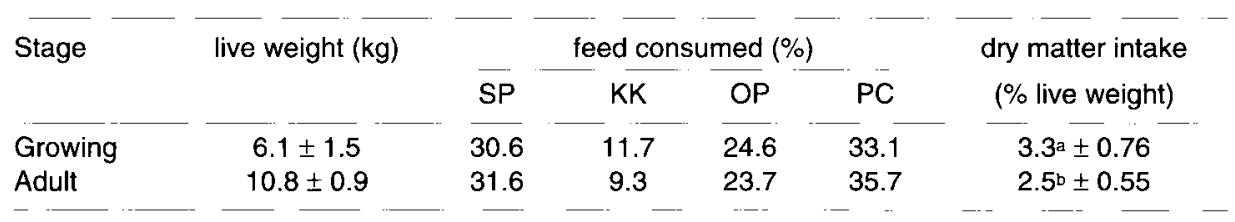

SP : sweet potato, KK : kangkong, OP : oil palm fruits, $\mathrm{PC}:$ commercial pellet.

a. b : significantly different at $P<0.05$. 